\title{
EDITOR'S NOTE: JOURNAL OVERVIEW
}

We welcome our readers and contributors to the International Journal of Telerehabilitation (IJT). As the title suggests,

IJT will focus on telerehabilitation -- one of the most promising new areas of evidence-based rehabilitation practice. The increasing excitement surrounding the potential applications of telerehabilitation is fueled by consumers' needs for access to service no matter where their location; a recognition of the benefits of service delivered in natural home and work environments; and the promise of service, teams and consultations that know no geographic boundaries.

\section{WHY IS "TELEREHABILITATION" THE FOCUS OF A NEW JOURNAL?}

IJT is a peer-reviewed journal dedicated to disseminating research, clinical studies and viewpoints about telerehabilitation. The journal will be published on a biannual basis, with the option for special topic issues.

Schmeler, Schein, McCue \& Betz (2009) aptly articulated the need to shine a bright light on telerehabilitation, in one of this volume's featured white papers:

"In an effort to clarify terminology and place telerehabilitation within the larger realm of telehealth, Jack Winters (2002) provided a conceptual view of emerging models of telehealth with two major subsets: telemedicine (i.e. delivery of clinical services) and telehealthcare (i.e. management of disability and health). When Winters wrote his now classic article, telerehabilitation was an emerging field, positioned within both telemedicine and telehealthcare. There have subsequently been advances in the conduct of practice, particularly in the areas of physical therapy, occupational therapy, audiology, speechlanguage pathology, and neuropsychology. We therefore propose that telerehabilitation warrants a separate and parallel identity under the "telehealth umbrella" alongside both telehealthcare and telemedicine."

Indeed, the size of the "telerehabilitation umbrella" continues to grow as more and more rehabilitation disciplines explore the possibilities of delivering assessment, therapy, and consultation at a distance. In addition to the disciplines of physical therapy, occupational therapy, audiology, speech-language pathology, and neuropsychology mentioned above, other disciplines with an interest in telerehabilitation include nutrition, vocational and rehabilitation counseling, rehabilitation engineers, architecture, and health information management. We expect that more will emerge, and welcome all to IJT.

\section{WHY AN "INTERNATIONAL" JOURNAL?}

The practice of telerehabilitation is not limited by geographic boundaries. Moreover, it can benefit persons living in non-traditional sites such as prisons; spacecraft and space stations; cruise ships; and submarines. Though current telerehabilitation efforts typically occur within state boundaries, the future is bright for expanded spans of distance-of-practice. Telerehabilitation has great potential for supporting the work of inter-disciplinary rehabilitation teams, and for delivering rehabilitation within natural, home-based environments. In this spirit, we welcome readers, contributors and reviewers from around the world. And, as is the case for this inaugural volume, we welcome the inspired contributions of students.

\section{WHO SPONSORS IJT?}

The International Journal of Telerehabilitation emerged as the result of the Rehabilitation Engineering Research Center on Telerehabilitation at the University of Pittsburgh, supported by a grant from the National Institute on Disability and Rehabilitation Research (NIDRR) (H133E040012).

IJT is registered with the US Library of Congress, and will be published biannually via a pro bono partnership with the University of Pittsburgh's University Library System (ULS), as a result of the generosity of Hillman University Librarian and Director Dr. Rush Miller, Associate University Librarian. The ULS is the 26th-largest academic research library in all of North America and the 16thlargest among the prestigious public institutions of the Association of American Universities. During the last decade, the ULS has hosted many digital archives and electronic publishing systems serving national and global research. 
The day-to-day work of IJT is conducted by a talented group of Senior Advisors, Associate Editors and Reviewers. Special thanks to: Associate Editor Dr. Michael Pramuka for management of this issue's research articles; Mr. Joseph Ruffing for layout and graphics; Timothy S. Deliyannides, Head of the ULS Department of Information Systems who serves as publisher; David Brienza PhD and Michael McCue, PhD, co-directors of the RERC at the Telerehabilitation University of Pittsburgh; and Katherine Seelman, Associate Dean for Disability Programs, University of Pittsburgh School of Health and Rehabilitation.

\author{
Sincerely, \\ Ellen R. Cohn, PhD \\ Editor
}

